\title{
Targeting ischemic penumbra Part II: selective drug delivery using liposome technologies
}

\author{
Shimin Liu, M.D., PhD ${ }^{1 *}$; Steven R. Levine, M.D² H. Richard Winn, M.D ${ }^{3^{*}}$ \\ 1 Department of Neurology, Boston University School of Medicine, Boston, USA \\ 2 Department of Neurology, Health Science Center, SUNY Brooklyn, New York, USA \\ 3 Department of Neurosurgery, Hofstra North Shore-LIJ School of Medicine, New York, USA
}

\begin{abstract}
In the present review (part II), we discuss the challenges and promises of selective drug delivery to ischemic brain tissue by liposome technologies. In part I of this serial review, we proposed "selective drug delivery to ischemic brain tissue" as a technique for neuroprotective treatment of acute ischemic stroke. To be effective, drugs must pass a series of barriers to arrive at ischemic brain. Brain ischemia results in metabolic and structural changes in the ischemic region, which cause additional obstacles for drug delivery. Liposome drug delivery system can pass these barriers and selectively target ischemic tissue by utilizing ischemia-induced changes in metabolism and molecular structure.
\end{abstract}

Keywords: Penumbra; drug delivery; liposome; pH-sensitive; blood-brain barrier.

Acute ischemic stroke causes irreversible injury in the ischemic core, but reversible injury in the peri-focal zone, the penumbra.(Astrup et al. 1981; Ebinger et al. 2009; Memezawa et al. 1992) Conventional drug delivery methods cause unwanted drug exposure to other tissue or brain regions. Because of limited blood supply to ischemic penumbra region, systemic high dose is often required for a drug to reach therapeutic levels in ischemic tissue, which may cause severe side effects and toxicity. Advanced drug delivery system using liposome techniques may achieve effective regional drug level without increasing systemic dose. Liposomal nanocarriers facilitate penetration of biological membrane, protect drugs from enzymatic and chemical degradation and albumin binding, and minimize drug exposures to non-target tissue. (Jain 2007; Tiwari and Amiji 2006) Following paragraphs discuss the challenges of selective drug delivery to ischemic brain tissue and the promises of liposome technologies in stroke therapy.

\section{The blood brain-barrier}

The blood brain barrier (BBB) consists of an endothelial enclosure and periendothelial accessories, which include pericytes, astrocytes, and a basal membrane. BBB strictly limits exchanges of sub- stance between blood and the brain. The endothelial cells of the BBB lack fenestrations and have both tight junctions and adherens junctions between the cells (Bazzoni and Dejana 2004; Kniesel and Wolburg 2000; Schulze and Firth 1993). BBB prevents passive diffusion of hydrophilic molecules and allows diffusion of uncharged small molecules (Grieb et al. 1985; Levin 1980). A thin basement membrane (i.e. basal lamina) surrounds the endothelial cells and pericytes supporting the abluminal surface of the endothelium. Astrocytes further encase this structure with endfeet interspersed with pericytes. (Hellstrom et al. 2001; Kacem et al. 1998). The BBB protects brain from foreign substance, but it also strictly limits therapeutic agents entering the brain.

Because of the lipidic nature of all biological membranes, including brain endothelial cell membrane, lipophilic molecules can diffuse across BBB whilst hydrophilic molecules utilize transporter-facilitated systems. (Pardridge 1999) Active transport of some endogenous or exogenous hydrophilic molecules crossing BBB can be in either influx or efflux directions. (Ohtsuki and Terasaki 2007) Some of these transporters, such as for amino acids, monocarboxylic acids, organic cations, hexoses, nucleosides, peptides, have been well studied and molecularly identi-

* Correspondence should be sent to: (Size 10 arial font, bold, italic)

Shimin Liu, M.D., Ph.D., Department of Neurology, Boston University School of Medicine, 715 Albany street, C329, Boston, MA02118; Tel: 617-638-7776; Fax: 617-638-5354; Email: lius@bu.edu.

H. Richard Winn, M.D., Director of Neurosurgery, 130 East 77th Street, Lenox Hill Hospital, New York, New York 10075; Tel: 212-434 3673; Fax: 212-434 2787; Email: hrwinn@Lenoxhill.net. 
fied. We refer the reader to the excellent review articles (Tamai and Tsuji 2000; Tsuji 2005) for more information of transport- assisted passage of BBB.

\section{BBB during cerebral ischemia}

Cerebral ischemia causes BBB damage and temporary $\mathrm{BBB}$ disruption. However, this temporary BBB opening causes edema, hemorrhagic transformation, and additional brain injury, therefore, it cannot be used for neuroprotective purpose. The area of the BBB disruption depends on injury intensity, injury type, and presence or absence of reperfusion. The BBB opening during ischemia in the absence of reperfusion occurs when the ischemic damage is already irreversible. For example, gadoliniumdiethylenetriamine penta-acetic acid (Gd-DTPA) extravasations was found grossly visible between 4.5 and $6 \mathrm{~h}$ after permanent MCAO (Kastrup et al. 1999). At this time, ischemic brain injury has already happened and is mostly irreversible. Reperfusion induced BBB disruption occurs after 3 and 48 hours of 2-h MCAO with reperfusion, with maximal opening at 48 hours and returns to normal by 14 days (Rosenberg et al. 1998). Gelatinase A (MMP-2) and TIMP-2 are associated with reperfusion induced BBB disruption(Rosenberg et al. 1998). After transient 20-min MCAO BBB disruption peaks at day 7 and resolves at day 14 after ischemia (Abulrob et al. 2008). BBB disruption during reperfusion stage is believed to be a precursor to hemorrhagic transformation $(\mathrm{HT})$ and poor outcome (Latour et al. 2004), which should be treated with adjunctive therapies.

\section{Methods for transducing the blood-brain barrier}

Traditional methods for opening BBB are invasive, inefficient, and non-selective. Transient osmotic opening of the BBB by arabinose or mannitol (Shinohara et al. 1979; Siegal et al. 2000), shunts (Zlotnik et al. 2008), or implanting microspheres (Beduneau et al. 2007; Emerich et al. 1999) to deliver therapeutic agents are invasive methods and have potential sideeffects. Osmotic agents can cause accumulation of mannitol in the cerebral tissue and increase edema, whilst implantations require surgery (Kaufmann and Cardoso 1992; Maioriello et al. 2002). These methods do not selectively open BBB for drug delivery or selectively target tissue.

More advanced methods for CNS drug delivery include altering the molecular structure of drugs to increase their membrane permeability, fusing the drug molecule with cell penetrating peptides, and encapsulating drugs into liposomal nanocarriers. Drugs can also compete to use a carrier system if their structure mimics that of an endogenous molecule. Drugs that cannot use an endogenous transport system may be fused to a molecule, such as transferrin or glucose (Rajkumar et al. 1995), which can be effectively transported across the BBB. In addition, monoclonal antibodies can be utilized to transport some drugs across the BBB via a receptor-mediated transport system (Lee et al. 2000; Pardridge 2005). In a similar manner, many cell penetrating peptides (CPPs) have been used for CNS drug delivery by conjugating to functioning therapeutic agents for cerebral ischemia (Esneault et al. 2008; Eum et al. 2004; Fan et al. 2006). Nanoliposomes and other nanoparticles can be utilized to deliver genes, proteins/peptides, and many other agents across the BBB. Nanoliposomes are engineered to enclose hydrophilic or ambiphilic agents within one or two lipid bilayers, similar to biological membranes.

The nanoliposome crosses the BBB by one of three methods: passive diffusion, endocytosis, or assisted passage with brain-targeting ligands (Beduneau et al. 2007; Chen et al. 2010; Markoutsa et al. 2011; Tamaru et al. 2010; Wong et al. 2010). These advanced methods for CNS drug delivery transduce BBB for a particular therapy, but they are not readily tissueselective or cell type-selective. It is possible to achieve significant improvements on the delivery specificity and efficiency by extensive modification and optimization of these methods. Selective BBB transduction for drug delivery that targets the diseased tissue will improve delivery efficiency and reduce adverse effect, and potentially can be used in ischemic stroke and other CNS disorders.

\section{Compromised blood supply and shrinkage of extracellular space}

In addition to the challenge of $\mathrm{BBB}$, ischemic brain tissue also has compromised blood flow that can further limit efficient drug delivery through blood supply. For example, the regional cerebral blood flow (rCBF) in the inner penumbra is only about $15 \mathrm{ml} / 100 \mathrm{~g} / \mathrm{min}$ (Murphy et al. 2006; Ohashi et al. 2005). Moreover, the extracellular space (ECS) is also decreased during ischemia (Thorne and Nicholson 2006; Zoremba et al. 2008). Ischemia causes cytotoxic edema that increases cell volume by $12 \%$ and reduces ECS by 50\%. (Homola et al. 2006) Theoretically, large dose will be needed for reaching an effective regional drug concentration; this increased dose may lead to severe drug toxicity. Many neuroprotectants have been tested effective in animal studies, but they cannot be used in stroke patients at effective dose because of drug-related severe toxicity.

\section{The advantages of liposomal drug delivery sys- tem}

Advanced technologies, such as $\mathrm{pH}$-sensitive nanoliposomes with enhanced BBB penetration and tissue selectivity, hold promises for ischemic stroke therapies. The lipid layer affords nanoliposomes BBB permeability for their encapsulated contents. Moreo- 
ver, these liposomal nanocarriers can acquire additional features through further modification, such as long circulating time, enhanced BBB penetration and ischemic tissue selectivity. The advantages of using nanoliposomes also include: 1). maintaining drugs in active state when being encapsulated inside the nanoliposome; 2). minimizing exposure to non-target tissue when tissue-selective liposomes being used; 3). providing a protective shell for the encapsulated contents, which prevents drugs from non-specific binding and enzymatic digestion; 4). being able to afford a high intraliposomal drug concentration. Therefore, nanoliposomes could be used as a basic means for drug delivery to ischemic stroke penumbra.(Jain 2007; Tiwari and Amiji 2006)

\section{Possibility of selective drug delivery to pe- numbral tissue}

Brain ischemia causes a metabolic shift towards anaerobic glycolysis, resulting in a lower intracellular $\mathrm{pH}$ in the ischemic brain tissue. Targeting at this property of ischemic brain tissue, liposomal nanocarriers may be optimized to selectively release their contents under acidic condition (Collins et al. 1989) similar to the microenvironment of ischemic brain tissue $(\mathrm{pH}<6.75)$ (Anderson et al. 1999). The fusogenic property of dioleoylphosphatidylethanolamine and transactivator of transcription (TAT) peptide will facilitate liposomes escaping from endosomes/lysosomes and normal cells (Boomer et al. 2009; Hatakeyama et al. 2009). These liposomes will release their cargos when they reach cytosols of ischemic cells that have a $\mathrm{pH}$ of around 6.75. The $\mathrm{pH}$ difference between extracellular and intracellular space in ischemic tissue is usually less than 0.5 unit in normoglycemic rats (Nedergaard et al. 1991), therefore, a portion of $\mathrm{pH}$-sensitive liposomes will deliver their cargos in the interstitial space.

These liposomal nanocarriers can gain additional features by incorporating functional molecules onto their membrane surfaces. Stroke-homing peptide (Hong et al. 2008) may be useful for selective drug delivery to ischemic brain tissue.

\section{The strategies for liposomal drug delivery to ischemic penumbra}

Currently there are no specially tailored nanoliposomes available for targeting ischemic stroke penumbra. A nanosized $\mathrm{pH}$-sensitive liposome commonly has 3-5 structural components, which include a basic lipid, a balancer, a stabilizer, optional function peptides, and an optional tracer. The basic lipid provides the sensitivity to acidic environment. The balancer is used to titrate $\mathrm{pH}$-sensitivity to the desired level. The stabilizer protects the nanoliposome from unwanted leakage and fusion. Optional function peptides may provide the nanoliposome additional abili- ties, such as enhanced BBB penetration and specific tissue targeting. Optional tracer can be a fluorescent lipid or fluorescent peptide.

\section{The basic lipid DOPE}

There are two basic lipids that provide nanoliposomes a sensitivity to acidic environment, the phosphatidylethanolamines (PE), and the dioleoylphosphatidylethanolamine (DOPE) (Drummond et al. 2000). PE based nanoliposomes tend to release their contents in a more acidic environment that may mimic ischemic core. DOPE based nanoliposomes can be optimized to release contents at mild acidic environment that may mimic ischemic penumbra. DOPE also has fusogenic property that facilitates liposomes escaping from endosomes and lysosomes (Boomer et al. 2009; Hatakeyama et al. 2009). The mild acidic activation and fusogenic property of DOPE plus residual blood flow in penumbral region give DOPEbased liposomes a higher chance of drug delivery to ischemic penumbra.

\section{Balancers and stabilizers:}

$\mathrm{N}$-succinyldioleoylphosphatidylethanolamine (sucDOPE), oleic acid (OA), palmitoylhomocysteine (PHC), cholesteryl hemisuccinate (CHEMS), and 1,2dioleoyl- or 1,2-dipalmitoyl-sn-3-succinylglycerol (DOSG or DPSG) are a few of the stabilizers that have been used to prepare $\mathrm{pH}$-sensitive liposome formulations. CHEMS-balanced $\mathrm{pH}$-sensitive nanoliposomes have been demonstrated for efficient intracellular delivery.(Costin et al. 2002) Poly (ethyleneglycol) (PEG) with different molecular weights is the most commonly used stabilizer and compatible with $\mathrm{pH}$-sensitive nanoliposomes.

PEG coated $\mathrm{pH}$-sensitive nanoliposomes for long circulatingn time.

Conventional or plain nanoliposomes are rapidly removed from circulation by the reticuloendothelial system (RES) and accumulate in the liver and spleen (Allen 1994; Cowens et al. 1993; Rahman et al. 1990), which limits their clinical applications. Recent progress in microencapsulation showed that introducing poly(ethylene-glycol) (PEG) onto nanoliposome surface can prevent nanoliposomes from opsonization (Allen et al. 1991; Blume and Cevc 1990; Blume and Cevc 1993; Torchilin et al. 1994), resulting in a long circulating time (Klibanov et al. 1990). PEG coated pH-sensitive nanoliposomes can be constructed using low pH-cleavable PEG or DSPE-PEG of a proper molar ratio. The working mechanisms of PEGylated $\mathrm{pH}$-sensitive nanoliposomes have been well illustrated. (Romberg et al. 2008; Sawant et al. 2006) The low pH-cleavable PEG is linked to its anchor by some special linkers, which include Diorthoester, Orthoester, Vinylether, Phosphoramidate, 
Hydrazone, b-thiopropionate. (Romberg et al. 2008) The DSPE-PEG coating is commonly used for constructing pH-sensitive liposomes. (Hong et al. 2002; Simoes et al. 2001; Slepushkin et al. 1997) The feature of $\mathrm{pH}$-dependent release is determined by DOPE/CHEMS ratio and PEG percentage. When DSPE-PEG is anchored on to $\mathrm{pH}$-sensitive liposome with a proper molar ratio, it may be randomly extracted and shed from liposome surface allowing uptake by cells when its anchor, the base lipid, becomes unstable in low $\mathrm{pH}$ environment. The fusogenic property of DOPE lipid (Boomer et al. 2009; Hatakeyama et al. 2009) may work synergically with TAT peptide to initiate internalization and intracellular delivery. The methodologies for construction and purification of DSPE-PEG-coated nanoliposomes have been well established. (Liang et al. 2004).

\section{Functional peptides}

Functional peptides for nanoliposomes can be classified into three categories: 1). cell-penetrating peptides (CPPs); 2). $\mathrm{pH}$-dependent fusion peptides; and 3). special function peptides. Here we just list the names of these peptides. More detailed and condensed information is available in related review papers(Deshayes et al. 2005; Drummond et al. 2000). CPPS include TAT, octarganine/R8, penetratin/ AntpHD, FGF/MTS, VP22, PEP-1, DynA, transportan, MAP, pegelin/SynB, pVEC, KALA, ppTG20, P1, MPG, trimer, and PrP. pH-dependent peptides and toxins include HA2, E1, G1/G2, G1/G2, G, E, gp36, TH8/TH9, GALA, SFP, Poly(Glu-Aiba-Leu-Aib, EGLA-I, EGLA-II, JTS1, VP-1, INF3, INF5, INF7, INF8, INF9, INF10, HA peptide, D4, E5, E5L, E5NN, E5CC, E5P, E5CN, AcE4K, poly(l-lysine), poly(Ihistidine), poly(acrylic acid) derivatives, succinylated poly(glycidol)s, and copolymers of $\mathrm{N}$ isopropylacrylamide (NIPAM). It may be practical to use CHEMS for titrating nanoliposomes to a desired $\mathrm{pH}$-sensitivity and leave these $\mathrm{pH}$-sensitive peptides as alternative approaches. Lysosomes-disrupting peptides have been reported to enhance intracellular delivery efficiency (Baru et al. 1998). Stroke-homing peptide is a special peptide that has been reported recently being able to targeting ischemic brain tissue. This peptide has the sequence "CLEVSRKNC"

TAT peptide targeted $\mathrm{pH}$-sensitive nanoliposomes for $B B B$ transduction. The human immunodeficiency virus-type 1 trans-activating transcriptional activator (HIV-1 TAT protein, an 86-mer polypeptide) (Frankel and Pabo 1988; Green and Loewenstein 1988) has been shown the ability for inducing cell transduction. Certain small regions of such proteins (10-16-mers) called protein transduction domains (PTDs) are responsible for TAT protein induced cell transduction. The minimal PTD of the TAT protein comprises 11 amino acids (Tyr-Gly-Arg-Lys-Lys-Arg-Arg-Gln-Arg-
Arg-Arg) functioning as a cell penetrating peptides (CPP). Fluorescently labeled TAT was visible throughout the brain 20 minutes after intraperitoneal (IP) administration in mice (Schwarze et al. 1999). Many other CPPs have also been discovered and synthesized (Deshayes et al. 2005). TAT peptide is the most widely used CPP among other CPPs for enhancing BBB penetration and for intracellular drug delivery (Herve et al. 2008). Moreover, relatively large 200-nm plain or polyethylene glycol-coated (PEGylated) nanoliposomes can be delivered into various cells by multiple TAT peptide molecules attached to the nanoliposome surface. (Hyndman et al. 2004; Levchenko et al. 2003; Torchilin 2002; Torchilin et al. 2001)

Stroke-homing peptide. Recently, the CLEVSRKNC (single letter sequence for Cys-Leu-Glu-Val-Ser-ArgLys-Asn-Cys) peptide has been demonstrated to be selective for ischemic brain tissue. (Hong et al. 2008)This peptide was screened from a phage peptide library based on a T7 415-1b phage vector displaying CX7C (C, cysteine; $X$, random peptides)(Pasqualini and Ruoslahti 1996). The CLEVSRKNC-phage preferentially targeted ischemic stroke tissue after intravenous administration in a rat MCA occlusion model. Because the CLEVSRKNC peptide is displayed on the phage membrane, theoretically it should be compatible with nanoliposome membrane layers. This means that CLEVSRKNC peptide may be incorporated onto nanoliposomes layers in ways similar to TAT peptide (Hyndman et al. 2004; Levchenko et al. 2003; Torchilin 2002; Torchilin et al. 2001) for localized drug delivery to ischemic brain tissue.

\section{Lipid and peptide tracers}

Lipids and peptides can be conjugated with some fluorescent dye to trace the distribution of nanoliposomes in cells or tissue. Rhodamine and Tetramethyl Rhodamine (TRITC) are commonly used for this purpose, and the synthesis and conjugating process are commercially available.

\section{Liposome size for penumbra drug delivery}

Liposome size is one of the factors that influence in vivo liposome distribution and drug delivery. The in vivo extracellular space width in rat brain is estimated 38-64 nm (Thorne and Nicholson 2006), at least 2fold greater than estimates from fixed tissue. Liposomes for brain drug delivery have been used in sizes of 50-150 nm (Chapat et al. 1991; Madhankumar et al. 2009), 64-73 nm (Xie et al. 2005), 120-147 nm (Puisieux et al. 1994), and 134-143 nm (Ko et al. 2009). Some of these liposomes sizes were bigger than extracellular space width. In such case, liposomes may mainly depend on endocytosis and transcellular route for drug delivery, similar to the me- 
chanism that allows their passage through the BBB (Patel et al. 2009). Because of the shrinkage of extracellular space (Thorne and Nicholson 2006; Zoremba et al. 2008), relatively small-sized liposomes may facilitate interstitial diffusion in ischemic tissue; but a smaller size also increases the risk of potential pulmonary toxicity (Nel et al. 2006).

\section{Concluding remarks}

The inability to selectively deliver $S$ therapeutic agents to brain tissue, especially during ischemic, has been a limitation in the treatment of stroke. However, advanced drug delivery tools provide a me- chanism to overcome these difficulties in stroke therapy. Because ischemia causes an acidic environment and residual blood flow exists in ischemic penumbral region, liposomal delivery system with a low $\mathrm{pH}$ dependent release feature can be used for targeting ischemic penumbra. The DOPE/CHEMS/DSPE-PEG system holds promises as a basic formula of $\mathrm{pH}$ dependent liposomes for stroke treatment. Other peptides, such as TATp and stroke homing peptide (STROKEp) may provide added features for such system. The proposed working mechanism is depicted in Fig. 1.

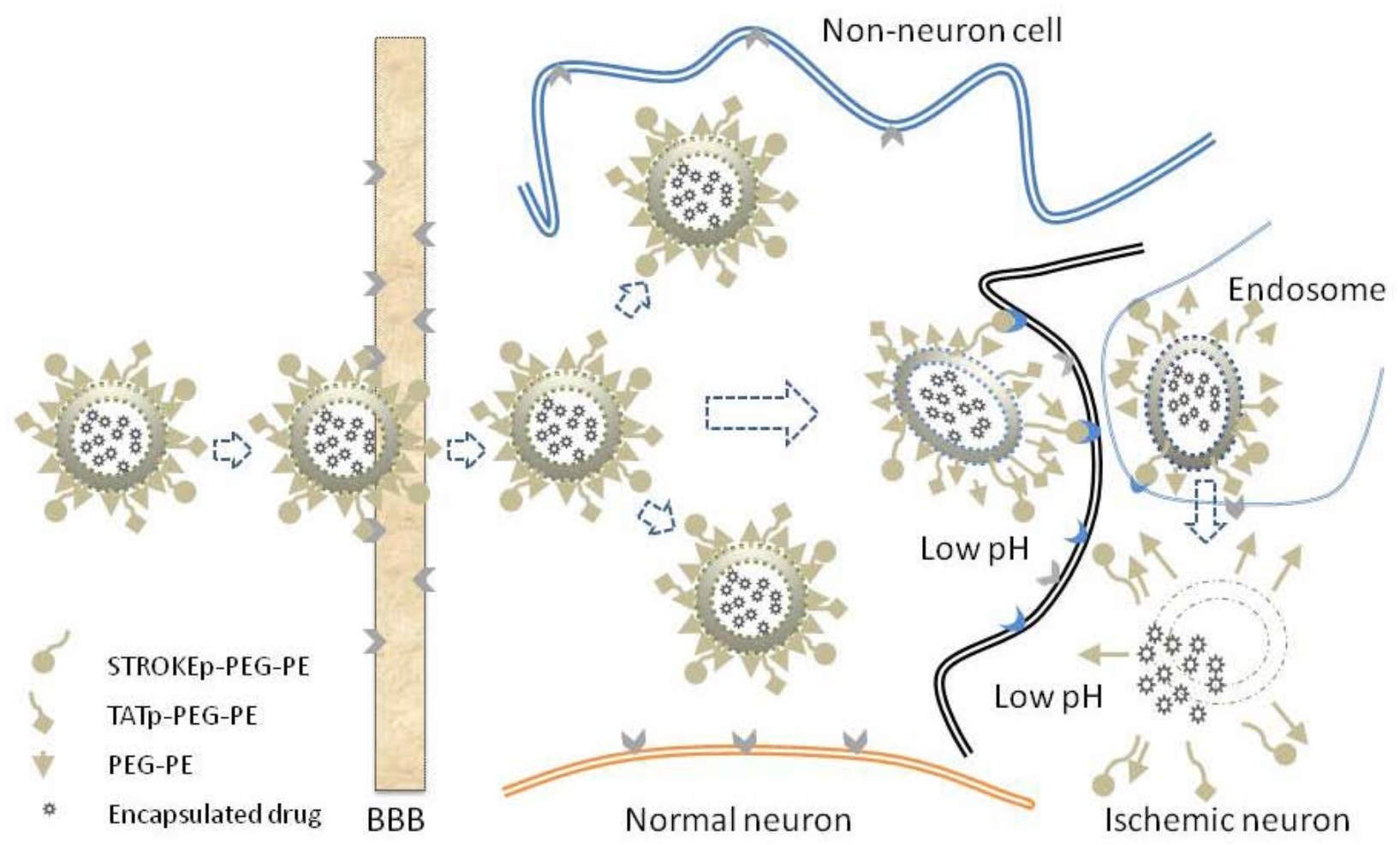

Fig.1 Diagram of selective drug delivery to ischemic penumbra by $\mathrm{pH}$-sensitive liposomes. TAT pep-tide (TATp) and stroke-homing peptide (STROKEp) are conjugated with PEG-PE on the surface of liposomes (TATp-PEG-PE and STROKEp-PEG-PE, respectively). TATp and the lipid layer facilitate drug-loaded liposome passage of the BBB and arrival at interstitial space. Liposomes remain stable in neutral $\mathrm{pH}$ environment, but they become destabilized in ischemic region due to low $\mathrm{pH}$. STROKEp helps liposomes targeting ischemic cells. TATp and lipid layer help liposomes uptaken by ischemic cells and escaping from endosomes. Destabilized pHsensitive liposomes release drugs in the cytosol of ischemic cells. A portion of liposomes may release drugs in extracellular space.

\section{Acknowledgement}

\section{Conflict of interest} $\begin{array}{ll}\text { This work was supported by NIH grant } \\ \text { 7R21NS065912-02, } & \text { 5T32NS051147-02 and NS }\end{array}$ 21076-24.

None

\section{References}


Abulrob A, Brunette E, Slinn J, Baumann E, Stanimirovic D. (2008) Dynamic analysis of the blood-brain barrier disruption in experimental stroke using time domain in vivo fluorescence imaging. Mol Imaging 7:248-262

Allen TM. (1994) Long-circulating (sterically stabilized) liposomes for targeted drug delivery. Trends Pharmacol Sci 15:215-220

Allen TM, Hansen C, Martin F, Redemann C, Yau-Young A. (1991) Liposomes containing synthetic lipid derivatives of poly(ethylene glycol) show prolonged circulation half-lives in vivo. Biochim Biophys Acta 1066:29-36

Anderson RE, Tan WK, Meyer FB. (1999) Brain acidosis, cerebral blood flow, capillary bed density, and mitochondrial function in the ischemic penumbra. J Stroke Cerebrovasc Dis 8:368-379

Astrup J, Siesjo BK, Symon L. (1981) Thresholds in cerebral ischemia - the ischemic penumbra. Stroke 12:723725

Baru M, Nahum O, Jaaro H, Sha'anani J, Nur I. (1998) Lysosome-disrupting peptide increases the efficiency of in-vivo gene transfer by liposome-encapsulated DNA. J Drug Target 6:191-199

Bazzoni G, Dejana E. (2004) Endothelial cell-to-cell junctions: molecular organization and role in vascular homeostasis. Physiol Rev 84:869-901

Beduneau A, Saulnier P, Benoit JP. (2007) Active targeting of brain tumors using nanocarriers. Biomaterials 28:4947-4967

Blume G, Cevc G. (1990) Liposomes for the sustained drug release in vivo. Biochim Biophys Acta 1029:91-97

Blume G, Cevc G. (1993) Molecular mechanism of the lipid vesicle longevity in vivo. Biochim Biophys Acta 1146:157-168

Boomer JA, Qualls MM, Inerowicz HD, Haynes RH, Patri VS, Kim JM, Thompson DH. (2009) Cytoplasmic delivery of liposomal contents mediated by an acid-labile cholesterol-vinyl ether-PEG conjugate. Bioconjug Chem 20:47-59

Chapat S, Frey V, Claperon N, Bouchaud C, Puisieux F, Couvreur P, Rossignol P, Delattre J. (1991) Efficiency of liposomal ATP in cerebral ischemia: bioavailability features. Brain Res Bull 26:339-342

Chen $\mathrm{H}$, Tang L, Qin Y, Yin Y, Tang J, Tang W, Sun X, Zhang Z, Liu J, He Q. (2010) Lactoferrin-modified procationic liposomes as a novel drug carrier for brain delivery. Eur J Pharm Sci 40:94-102

Collins D, Maxfield F, Huang L. (1989) Immunoliposomes with different acid sensitivities as probes for the cellular endocytic pathway. Biochim Biophys Acta 987:4755

Costin GE, Trif M, Nichita N, Dwek RA, Petrescu SM. (2002) $\mathrm{pH}$-sensitive liposomes are efficient carriers for endoplasmic reticulum-targeted drugs in mouse melanoma cells. Biochem Biophys Res Commun 293:918-923
Cowens JW, Creaven PJ, Greco WR, Brenner DE, Tung Y, Ostro M, Pilkiewicz F, Ginsberg R, Petrelli N. (1993) Initial clinical (phase I) trial of TLC D-99 (doxorubicin encapsulated in liposomes). Cancer Res 53:27962802

Deshayes S, Morris MC, Divita G, Heitz F. (2005) Cellpenetrating peptides: tools for intracellular delivery of therapeutics. Cell Mol Life Sci 62:1839-1849

Drummond DC, Zignani M, Leroux J. (2000) Current status of $\mathrm{pH}$-sensitive liposomes in drug delivery. Prog Lipid Res 39:409-460

Ebinger M, De Silva DA, Christensen S, Parsons MW, Markus R, Donnan GA, Davis SM. (2009) Imaging the penumbra - strategies to detect tissue at risk after ischemic stroke. J Clin Neurosci 16:178-187

Emerich DF, Tracy MA, Ward KL, Figueiredo M, Qian R, Henschel C, Bartus RT. (1999) Biocompatibility of poly (DL-lactide-co-glycolide) microspheres implanted into the brain. Cell Transplant 8:47-58

Esneault E, Castagne V, Moser P, Bonny C, Bernaudin M. (2008) D-JNKi, a peptide inhibitor of C-Jun N-terminal kinase, promotes functional recovery after transient focal cerebral ischemia in rats. Neuroscience 152:308320

Eum WS, Kim DW, Hwang IK, Yoo KY, Kang TC, Jang SH, Choi HS, Choi SH, Kim YH, Kim SY, Kwon HY, Kang $\mathrm{JH}$, Kwon OS, Cho SW, Lee KS, Park J, Won MH, Choi SY. (2004) In vivo protein transduction: biologically active intact pep-1-superoxide dismutase fusion protein efficiently protects against ischemic insult. Free Radic Biol Med 37:1656-1669

Fan YF, Lu CZ, Xie J, Zhao YX, Yang GY. (2006) Apoptosis inhibition in ischemic brain by intraperitoneal PTDBIR3-RING (XIAP). Neurochem Int 48:50-59

Frankel AD, Pabo CO. (1988) Cellular uptake of the tat protein from human immunodeficiency virus. Cell 55:1189-1193

Green M, Loewenstein PM. (1988) Autonomous functional domains of chemically synthesized human immunodeficiency virus tat trans-activator protein. Cell 55:11791188

Grieb P, Forster RE, Strome D, Goodwin CW, Pape PC. (1985) $\mathrm{O} 2$ exchange between blood and brain tissues studied with 1802 indicator-dilution technique. J Appl Physiol 58:1929-1941

Hatakeyama $\mathrm{H}$, Ito $\mathrm{E}$, Akita $\mathrm{H}$, Oishi M, Nagasaki Y, Futaki $\mathrm{S}$, Harashima $\mathrm{H}$. (2009) A pH-sensitive fusogenic peptide facilitates endosomal escape and greatly enhances the gene silencing of siRNA-containing nanoparticles in vitro and in vivo. $\mathrm{J}$ Control Release 139:127-132

Hellstrom M, Gerhardt H, Kalen M, Li X, Eriksson U, Wolburg H, Betsholtz C. (2001) Lack of pericytes leads to endothelial hyperplasia and abnormal vascular morphogenesis. J Cell Biol 153:543-553 
Herve F, Ghinea N, Scherrmann JM. (2008) CNS delivery via adsorptive transcytosis. Aaps J 10:455-472

Homola A, Zoremba N, Slais K, Kuhlen R, Sykova E. (2006) Changes in diffusion parameters, energy-related metabolites and glutamate in the rat cortex after transient hypoxia/ischemia. Neurosci Lett 404:137-142

Hong HY, Choi JS, Kim YJ, Lee HY, Kwak W, Yoo J, Lee JT, Kwon TH, Kim IS, Han HS, Lee BH. (2008) Detection of apoptosis in a rat model of focal cerebral ischemia using a homing peptide selected from in vivo phage display. J Control Release 131:167-172

Hyndman L, Lemoine JL, Huang L, Porteous DJ, Boyd AC, Nan X. (2004) HIV-1 Tat protein transduction domain peptide facilitates gene transfer in combination with cationic liposomes. J Control Release 99:435-444

Jain KK. (2007) Nanobiotechnology-based drug delivery to the central nervous system. Neurodegener Dis 4:287291

Kacem K, Lacombe P, Seylaz J, Bonvento G. (1998) Structural organization of the perivascular astrocyte endfeet and their relationship with the endothelial glucose transporter: a confocal microscopy study. Glia 23:1-10

Kastrup A, Engelhorn T, Beaulieu C, de Crespigny A, Moseley ME. (1999) Dynamics of cerebral injury, perfusion, and blood-brain barrier changes after temporary and permanent middle cerebral artery occlusion in the rat. J Neurol Sci 166:91-99

Kaufmann AM, Cardoso ER. (1992) Aggravation of vasogenic cerebral edema by multiple-dose mannitol. J Neurosurg 77:584-589

Klibanov AL, Maruyama K, Torchilin VP, Huang L. (1990) Amphipathic polyethyleneglycols effectively prolong the circulation time of liposomes. FEBS Lett 268:235237

Kniesel U, Wolburg H. (2000) Tight junctions of the bloodbrain barrier. Cell Mol Neurobiol 20:57-76

Ko YT, Bhattacharya R, Bickel U. (2009) Liposome encapsulated polyethylenimine/ODN polyplexes for brain targeting. J Control Release 133:230-237

Latour LL, Kang DW, Ezzeddine MA, Chalela JA, Warach S. (2004) Early blood-brain barrier disruption in human focal brain ischemia. Ann Neurol 56:468-477

Lee $\mathrm{HJ}$, Engelhardt B, Lesley J, Bickel U, Pardridge WM. (2000) Targeting rat anti-mouse transferrin receptor monoclonal antibodies through blood-brain barrier in mouse. J Pharmacol Exp Ther 292:1048-1052

Levchenko TS, Rammohan R, Volodina N, Torchilin VP. (2003) Tat peptide-mediated intracellular delivery of liposomes. Methods Enzymol 372:339-349

Levin VA. (1980) Relationship of octanol/water partition coefficient and molecular weight to rat brain capillary permeability. J Med Chem 23:682-684

Liang W, Levchenko TS, Torchilin VP. (2004) Encapsulation of ATP into liposomes by different methods: opti- mization of the procedure. $J$ Microencapsul 21:251261

Madhankumar AB, Slagle-Webb B, Wang X, Yang QX, Antonetti DA, Miller PA, Sheehan JM, Connor JR. (2009) Efficacy of interleukin-13 receptor-targeted liposomal doxorubicin in the intracranial brain tumor model. Mol Cancer Ther 8:648-654

Maioriello AV, Chaljub G, Nauta HJ, Lacroix M. (2002) Chemical shift imaging of mannitol in acute cerebral ischemia. Case report. J Neurosurg 97:687-691

Markoutsa E, Pampalakis G, Niarakis A, Romero IA, Weksler B, Couraud PO, Antimisiaris SG. (2011) Uptake and permeability studies of BBB-targeting immunoliposomes using the hCMEC/D3 cell line. Eur J Pharm Biopharm 77:265-274

Memezawa H, Minamisawa H, Smith ML, Siesjo BK. (1992) Ischemic penumbra in a model of reversible middle cerebral artery occlusion in the rat. Exp Brain Res 89:6778

Murphy BD, Fox AJ, Lee DH, Sahlas DJ, Black SE, Hogan MJ, Coutts SB, Demchuk AM, Goyal M, Aviv RI, Symons S, Gulka IB, Beletsky V, Pelz D, Hachinski V, Chan R, Lee TY. (2006) Identification of penumbra and infarct in acute ischemic stroke using computed tomography perfusion-derived blood flow and blood volume measurements. Stroke 37:1771-1777

Nedergaard M, Kraig RP, Tanabe J, Pulsinelli WA. (1991) Dynamics of interstitial and intracellular $\mathrm{pH}$ in evolving brain infarct. Am J Physiol 260:R581-588

Nel A, Xia T, Madler L, Li N. (2006) Toxic potential of materials at the nanolevel. Science 311:622-627

Ohashi M, Tsuji A, Kaneko M, Matsuda M. (2005) Threshold of regional cerebral blood flow for infarction in patients with acute cerebral ischemia. $J$ Neuroradiol 32:337-341

Ohtsuki S, Terasaki T. (2007) Contribution of carriermediated transport systems to the blood-brain barrier as a supporting and protecting interface for the brain; importance for CNS drug discovery and development. Pharm Res 24:1745-1758

Pardridge WM. (1999) Blood-brain barrier biology and methodology. J Neurovirol 5:556-569

Pardridge WM. (2005) The blood-brain barrier: bottleneck in brain drug development. NeuroRx 2:3-14

Pasqualini R, Ruoslahti E. (1996) Organ targeting in vivo using phage display peptide libraries. Nature 380:364366

Patel MM, Goyal BR, Bhadada SV, Bhatt JS, Amin AF. (2009) Getting into the brain: approaches to enhance brain drug delivery. CNS Drugs 23:35-58

Puisieux F, Fattal E, Lahiani M, Auger J, Jouannet P, Couvreur P, Delattre J. (1994) Liposomes, an interesting tool to deliver a bioenergetic substrate (ATP). in vitro and in vivo studies. J Drug Target 2:443-448 
Rahman A, Treat J, Roh JK, Potkul LA, Alvord WG, Forst D, Woolley PV. (1990) A phase I clinical trial and pharmacokinetic evaluation of liposome-encapsulated doxorubicin. J Clin Oncol 8:1093-1100

Rajkumar K, Barron D, Lewitt MS, Murphy LJ. (1995) Growth retardation and hyperglycemia in insulin-like growth factor binding protein-1 transgenic mice. Endocrinology 136:4029-4034

Romberg B, Hennink WE, Storm G. (2008) Sheddable coatings for long-circulating nanoparticles. Pharm Res 25:55-71

Rosenberg GA, Estrada EY, Dencoff JE. (1998) Matrix metalloproteinases and TIMPS are associated with bloodbrain barrier opening after reperfusion in rat brain. Stroke 29:2189-2195

Sawant RM, Hurley JP, Salmaso S, Kale A, Tolcheva E, Levchenko TS, Torchilin VP. (2006) "SMART" drug delivery systems: double-targeted $\mathrm{pH}$-responsive pharmaceutical nanocarriers. Bioconjug Chem 17:943-949

Schulze C, Firth JA. (1993) Immunohistochemical localization of adherens junction components in blood-brain barrier microvessels of the rat. J Cell Sci 104 ( Pt 3):773-782

Schwarze SR, Ho A, Vocero-Akbani A, Dowdy SF. (1999) In vivo protein transduction: delivery of a biologically active protein into the mouse. Science 285:1569-1572

Shinohara M, Dollinger B, Brown G, Rapoport S, Sokoloff L. (1979) Cerebral glucose utilization: local changes during and after recovery from spreading cortical depression. Science 203:188-190

Siegal T, Rubinstein R, Bokstein F, Schwartz A, Lossos A, Shalom E, Chisin R, Gomori JM. (2000) In vivo assessment of the window of barrier opening after osmotic blood-brain barrier disruption in humans. J Neurosurg 92:599-605

Tamai I, Tsuji A. (2000) Transporter-mediated permeation of drugs across the blood-brain barrier. J Pharm Sci 89:1371-1388

Tamaru M, Akita H, Fujiwara T, Kajimoto K, Harashima $\mathrm{H}$. (2010) Leptin-derived peptide, a targeting ligand for mouse brain-derived endothelial cells via macropinocytosis. Biochem Biophys Res Commun 394:587-592
Thorne RG, Nicholson C. (2006) In vivo diffusion analysis with quantum dots and dextrans predicts the width of brain extracellular space. Proc Natl Acad Sci U S A 103:5567-5572

Tiwari SB, Amiji MM. (2006) A review of nanocarrier-based CNS delivery systems. Curr Drug Deliv 3:219-232

Torchilin VP. (2002) TAT peptide-modified liposomes for intracellular delivery of drugs and DNA. Cell Mol Biol Lett 7:265-267

Torchilin VP, Omelyanenko VG, Papisov MI, Bogdanov AA, Jr., Trubetskoy VS, Herron JN, Gentry CA. (1994) Poly(ethylene glycol) on the liposome surface: on the mechanism of polymer-coated liposome longevity. Biochim Biophys Acta 1195:11-20

Torchilin VP, Rammohan R, Weissig V, Levchenko TS. (2001) TAT peptide on the surface of liposomes affords their efficient intracellular delivery even at low temperature and in the presence of metabolic inhibitors. Proc Natl Acad Sci U S A 98:8786-8791

Tsuji A. (2005) Small molecular drug transfer across the blood-brain barrier via carrier-mediated transport systems. NeuroRx 2:54-62

Wong HL, Chattopadhyay N, Wu XY, Bendayan R. (2010) Nanotechnology applications for improved delivery of antiretroviral drugs to the brain. Adv Drug Deliv Rev 62:503-517

Xie Y, Ye L, Zhang X, Cui W, Lou J, Nagai T, Hou X. (2005) Transport of nerve growth factor encapsulated into liposomes across the blood-brain barrier: in vitro and in vivo studies. J Control Release 105:106-119

Zlotnik A, Gruenbaum SE, Artru AA, Leibovitz A, Shapira Y. (2008) The Position of Arterial Line Significantly Influences Neurological Assessment in Rats. ASA Annual Meeting Abstract 109:A486

Zoremba N, Homola A, Slais K, Vorisek I, Rossaint R, Lehmenkuhler A, Sykova E. (2008) Extracellular diffusion parameters in the rat somatosensory cortex during recovery from transient global ischemia/hypoxia. $J$ Cereb Blood Flow Metab 28:1665-1673 